\title{
Correction to: Hydroxypropylmethylcellulose as a film and hydrogel carrier for ACP nanoprecursors to deliver biomimetic mineralization
}

Zhe Wang ${ }^{1 \dagger}$, Zihuai Zhou ${ }^{1 \dagger}$, Jiayan Fan ${ }^{1}$, Leiqing Zhang ${ }^{1}$, Zhixin Zhang ${ }^{1}$, Zhifang Wu ${ }^{1}$, Ying Shi ${ }^{1}$, Haiyan Zheng ${ }^{1}$, Zhengyi Zhang ${ }^{1}$, Ruikang Tang ${ }^{2}$ and Baiping Fu ${ }^{1 *}$ (1)

\section{Correction to: J Nanobiotechnol (2021) 19:385}

https://doi.org/10.1186/s12951-021-01133-7

Following publication of the original article [1], the authors would like to correct the competing interest.

The correct version of competing interest is given in this erratum.

\section{Competing interests}

Authors (B. Fu, Z. Wang, J. Fan and Z. Wu) declared that they have applied patents concerning mineralizing film for mineralization applications in China (No: ZL201610893384.3).

The original article is revised.

\section{Author details}

${ }^{1}$ Stomatology Hospital, School of Stomatology, Zhejiang University School of Medicine, Zhejiang Provincial Engineering Research Center for Oral
Biomaterials and Devices, Zhejiang Provincial Clinical Research Center for Oral Diseases, Key Laboratory of Oral Biomedical Research of Zhejiang Province, Cancer Center of Zhejiang University, Hangzhou 310006, China. ${ }^{2}$ Department of Chemistry, Zhejiang University, Hangzhou 310027, Zhejiang, China.

Published online: 18 December 2021

\section{Reference}

1. Wang Z, Zhou Z, Fan J, Zhang L, Zhang Z, Wu Z, Shi Y, Zheng H, Zhang Z, Tang R, Fu B. Hydroxypropylmethylcellulose as a film and hydrogel carrier for ACP nanoprecursors to deliver biomimetic mineralization. J Nanobiotechnol. 2021;19(1):1-5.

\section{Publisher's Note}

Springer Nature remains neutral with regard to jurisdictional claims in published maps and institutional affiliations.

\footnotetext{
*Correspondence: fbp@zju.edu.cn

${ }^{\dagger}$ Zhe Wang and Zihuai Zhou contributed equally to this work

${ }^{1}$ Stomatology Hospital, School of Stomatology, Zhejiang University School of Medicine, Zhejiang Provincial Engineering Research Center for Oral Biomaterials and Devices, Zhejiang Provincial Clinical Research Center for Oral Diseases, Key Laboratory of Oral Biomedical Research of Zhejiang Province, Cancer Center of Zhejiang University, Hangzhou 310006, China

Full list of author information is available at the end of the article
}

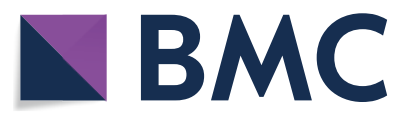

(c) The Author(s) 2021. Open Access This article is licensed under a Creative Commons Attribution 4.0 International License, which permits use, sharing, adaptation, distribution and reproduction in any medium or format, as long as you give appropriate credit to the original author(s) and the source, provide a link to the Creative Commons licence, and indicate if changes were made. The images or other third party material in this article are included in the article's Creative Commons licence, unless indicated otherwise in a credit line to the material. If material is not included in the article's Creative Commons licence and your intended use is not permitted by statutory regulation or exceeds the permitted use, you will need to obtain permission directly from the copyright holder. To view a copy of this licence, visit http://creativecommons.org/licenses/by/4.0/. The Creative Commons Public Domain Dedication waiver (http://creativeco mmons.org/publicdomain/zero/1.0/) applies to the data made available in this article, unless otherwise stated in a credit line to the data. 